\title{
Genome Diversity and Intra- and Interspecies Recombination Events in Grapevine fanleaf virus
}

\author{
Tefera A. Mekuria, Linga R. Gutha, Robert R. Martin, and Rayapati A. Naidu
}

First, second, and fourth authors: Department of Plant Pathology, Irrigated Agriculture Research and Extension Center, Washington State University, Prosser, WA 99350; and third author: United States Department of Agriculture-Agricultural Research Service, Horticulture Crops Research Laboratory, Corvallis, OR 97330.

Accepted for publication 14 August 2009.

\begin{abstract}
Mekuria, T. A., Gutha, L. R., Martin, R. R., and Naidu, R. A. 2009. Genome diversity and intra- and interspecies recombination events in Grapevine fanleaf virus. Phytopathology 99:1394-1402.

Grapevine fanleaf virus (GFLV) was documented in self-rooted vines of four grapevine (Vitis vinifera) cultivars in eastern Washington. GFLV was found as mixed infection in cvs. Pinot Noir, Chardonnay, and Cabernet Franc and as single infections in cv. Merlot. Fanleaf disease symptoms were only observed in the first two cultivars. The spatial distribution of GFLV-infected grapevines was random, suggesting primary spread through planting virus-infected cuttings rather than infield transmission. RNA1 sequences of Washington isolates showed 87 to

$89 \%$ nucleotide sequence identity between them and with strain F13. RNA2 of Washington isolates was variable in size, showing 85 to $99 \%$ sequence identity between them and 81 to $92 \%$ with other isolates. As in other GFLV isolates, three conserved putative stem-loop structures were present in the $5^{\prime}$ noncoding regions of both RNAs of Washington isolates. Phylogenetic incongruence of GFLV isolates from Washington in $2 \mathrm{~A}^{\mathrm{HP}}$ and $2 \mathrm{~B}^{\mathrm{MP}}$-based trees and identification of putative recombination events suggested that their genomic RNA2 originated from inter- and intraspecies recombination events between GFLV, Grapevine deformation virus, and Arabis mosaic virus. These results confirm interspecies recombination in RNA2 of grapevine-infecting nepoviruses as an important strategy for GFLV evolution.
\end{abstract}

Grapevine fanleaf disease is a devastating virus disease of grapevine (Vitis spp.) in many grape-growing areas around the world (1). The virus causes a wide range of symptoms that include reduced vigor and general decline of vines; malformation of leaves, canes, and berries; and reduced yields due to poor berry set. The reduction in yield varies depending on the severity of symptoms and grape cultivar but $>80 \%$ reduction has been recorded (7). Foliar symptoms produced by the disease are highly variable depending on cultivar and seasonal influences, and include fan-like distortions of leaves, ringspots, line patterns, vein banding, yellowish mottling, and mosaic in different cultivars. Infected grapevines exhibit foliar symptoms early in the season that tend to fade during the summer and fall. Plant-to-plant spread of the virus in the vineyard occurs only by the ectoparasitic dagger nematode Xiphinema index $(17,27)$. The virus also is transmitted efficiently by grafting and via the distribution of infected vegetative propagation materials.

Grapevine fanleaf virus (GFLV, genus Nepovirus, family Comoviridae) (21) is the causal agent of grapevine fanleaf disease. The genome of GFLV is composed of two single-stranded, positive-sense RNAs, termed RNA1 and RNA2 (Fig. 1). They are encapsidated separately in polyhedral virus particles of $\approx 28 \mathrm{~nm}$ in diameter (41). The size of RNA1 is 7,342 nucleotides (nt) but RNA2 is variable between 3,774 and 3,806 nt $(44,47,57)$. Both

Corresponding author: R.A. Naidu; E-mail address: naidu@wsu.edu

The GenBank accession numbers for the sequences reported in this article are GQ332364 to GQ332373.

* The $\boldsymbol{e}$-Xtra logo stands for "electronic extra" and indicates that the online version contains a figure showing the symptoms produced by Grapevine fanleaf virus in wine grape cultivars

doi:10.1094/PHYTO-99-12-1394

(C) 2009 The American Phytopathological Society
RNAs are polyadenylated at their $3^{\prime}$ end and carry a small protein, VPg, covalently linked to their $5^{\prime}$ ends (36). It has been shown that RNA1 can replicate autonomously in protoplasts, whereas RNA2 replication occurs only when present together with RNA1 (55). However, both RNAs are required for systemic infection of plants.

RNA1 and RNA2 are monocistronic and each encodes a single polyprotein that is processed proteolytically into functional proteins required to complete the virus life cycle. The RNA1encoded P1 polyprotein includes in its $\mathrm{C}$-terminal region the domains for the putative nucleotide triphosphate-binding protein $\left(\mathrm{NTB}\right.$ or $\left.1 \mathrm{~B}^{\mathrm{Hel}}\right)$, the small viral protein linked to the genome $\left(1 \mathrm{C}^{\mathrm{VPg}}\right)$, the proteinase $\left(1 \mathrm{D}^{\mathrm{Pro}}\right)$, and the RNA-dependent RNA polymerase $\left(1 \mathrm{E}^{\mathrm{Pol}}\right)$ (Fig. 1). The functional role of the N-terminal region of $\mathrm{P} 1$ polyprotein is less characterized, although recent studies predicted two protein domains upstream of the NTB domain, designated as $\mathrm{X} 1$ and $\mathrm{X} 2$, separated by putative cleavage sites $\mathrm{C} / \mathrm{A}$ and G/A between X1-X2 and X2-NTB domains, respectively (56). The RNA2-encoded $\mathrm{P} 2$ polyprotein contains (from the $\mathrm{N}$ - to $\mathrm{C}$-terminus) the domains for the homing protein $\left(2 \mathrm{~A}^{\mathrm{HP}}\right)$, the movement protein $\left(2 \mathrm{~B}^{\mathrm{MP}}\right)$, and the coat protein $\left(2 \mathrm{C}^{\mathrm{CP}}\right)$ (Fig. 1) (26). The $2 \mathrm{~A}^{\mathrm{HP}}$ localizes in the replication site and has been implicated in RNA1-dependent replication of RNA2 (13). The $2 \mathrm{~B}^{\mathrm{MP}}$ is a movement protein and is found in tubules observed in the plasmodesmata (43). The $2 \mathrm{C}^{\mathrm{CP}}$ is a multifunctional coat protein that is important in specific transmission by $X$. index, encapsidation of genomic RNAs, and systemic spread in plants $(2,4,8,17)$.

GFLV has been documented as a broad range of molecular variants in several countries in Europe, Africa, the Middle East, and North America $(3,12,24,32,37,40,51)$. GFLV, but not other nepoviruses, was identified so far in Washington State (30) vineyards and poses a potential threat to the sustainability of the wine grape industry that has a $\$ 3$ billion-plus impact to the state's economy. GFLV could also become a major threat to the wine grape industry in the Pacific Northwest of the United States due 
to increased exchange of vegetative cuttings to meet the expansion of wine grape acreage in the region. A detailed assessment of virus isolates present in Washington is essential for designing effective sanitation strategies for preventing the spread of fanleaf disease. Such measures are especially critical for Washington vineyards where grapevines are grown as own-rooted plants, in contrast to the use of suitable rootstock resistant to nematode vector feeding for limiting GFLV transmission in other grapegrowing regions (42).

In this study, GFLV isolates collected from four different wine grape cultivars were characterized at the molecular level. The fulllength sequences of RNA1 and RNA2 obtained from these cultivars were compared with corresponding sequences of grapevineinfecting nepoviruses available in GenBank. The results indicated the presence of distinct genetic variants of GFLV, some of which have shown interspecies recombination in the $2 \mathrm{~A}^{\mathrm{HP}}$ and $2 \mathrm{~B}^{\mathrm{MP}}$ genes with sequences from Grapevine deformation virus (GDefV) and Arabis mosaic virus (ArMV) $(9,10,15)$, two subgroup A nepoviruses closely related to GFLV (9). To the best of our knowledge, this is the first report of interspecies recombination between GFLV and GDefV. The results presented in this study extend current knowledge on the molecular diversity of GFLV and, together with a recent report (53), highlight interspecies recombination as a potential strategy for GFLV diversity and evolution.

\section{MATERIALS AND METHODS}

Plant samples. Samples were collected from individual grapevines of four wine grape cultivars during 2007 and 2008 seasons. Cultivars Pinot Noir, Chardonnay, Cabernet Franc, and Merlot were planted in 1960, 1982, 1999, and 2007, respectively, in geographically separate vineyards. They are grown as own-rooted plants, which is a common viticultural practice in Washington State.

Sample extraction and virus testing. The petioles of leaves and cambial scrapings of hardwood cuttings collected from individual grapevines were pooled and extracts prepared with the aid of a HOMEX 6 homogenizer (BIOREBA AG, Reinach BL1, Switzerland) using the procedure described previously (45). Onestep, single-tube reverse-transcription polymerase chain reaction (RT-PCR) assay was carried out in a $25-\mu \mathrm{l}$ volume using $2 \mu \mathrm{l}$ of the denatured extract as described earlier $(30,46)$. The primers GFLV2231F (5'-ACCGGATTGACGTGGGTGAT-3') and GFLV2533R (5'-CCAAAGTTGGTTTCCCAAGA-3') were used to amplify a 322 -bp fragment specific to the $2 \mathrm{C}^{\mathrm{CP}}$ gene of GFLV RNA2 for the detection of virus in grapevine samples.

RT-PCR amplification, molecular cloning, and sequencing of GFLV RNA1 and RNA2. Extracts from GFLV-positive grape- vine leaves were used for RT-PCR amplification of RNA1 and RNA2. Unless otherwise mentioned, the virus derived from individual grapevine was considered to be one isolate. The complete RNA1 and RNA2 sequences from each isolate were amplified as several cDNA overlapping fragments. Initially, primers for RNA1 and RNA2 amplification were designed based on the sequence of isolate F13 of GFLV (GenBank accession nos. NC_003615 and NC_003623). Amplicons were cloned into pCR2.1 vector using a TOPO TA cloning kit (Invitrogen Corp., Carlsbad, CA) and transformed into Escherichia coli following the manufacturer's instructions. Recombinant clones were screened for the presence of inserts of the expected size by colony PCR using M13F and M13R primers. Plasmid DNA was purified from positive recombinant clones using the QIAprep Spin Miniprep Kit (Qiagen Inc., Valencia, CA). The large-size cDNA clones of both RNAs were sequenced by the primer-walking method. Based on the sequence information generated, additional primers were designed for use in RT-PCR amplification of regions of RNA1 and RNA2 that were not covered by the cDNA clones. Three clones for each isolate were sequenced in both orientations. When necessary, additional clones were sequenced to resolve ambiguities in RNA1 and RNA2 sequences. Sequences were edited and assembled using ContigExpress module in the VectorNTI sequence analysis software package (Invitrogen Corp.).

Rapid amplification of cDNA ends of RNA1 and RNA2. The exact $5^{\prime}$ and $3^{\prime}$ end sequences of GFLV RNA1 and RNA2 was determined using $5^{\prime}$ and $3^{\prime}$ rapid amplification of cDNA (RACE) kit (Roche Diagnostics, Mannheim, Germany). For 5' RACE, first-strand cDNA synthesis was performed using the RNA1specific primer (5'-TTAACAAGACGTGTGCTCATC-3') complementary to nucleotides 338 to 358 of isolate F13 of GFLV and RNA2-specific primer (5'-CAGCCATTGTTCAACGGAA-3') complementary to nucleotides 300 to 318 of isolate WACF2142 of GFLV. GFLV-specific cDNA was amplified by PCR using the RNA1-specific primer (5'-ATCTTGAGTTTCTTAAACTCTTCAC-3') complementary to nucleotides 51 to 75 of isolate $F 13$, the RNA2-specific primer (5'-GCTAAACAAATAA/GAGCGCAA$3^{\prime}$ ) complementary to nucleotides 152 to 171 of strain WAPN173 of GFLV, and the anchor primer supplied with the kit. For 3' RACE, first-strand cDNA synthesis for both RNA1 and RNA2 was initiated using the Oligo (dT)-anchor primer, and virusspecific DNA was amplified using the PCR anchor primer supplied with the kit and either RNA1-specific primer (5'-ATGCTTTTAGTGGCGACAGTG-3') identical to nucleotides 7242 to 7262 of F13 strain of GFLV or RNA2-specific primer (5'TTGCAGGAGCAAACCCAAACACTC-3') identical to nucleotides 3411 to 3434 of F13 strain of GFLV. The 5' and 3' RACE
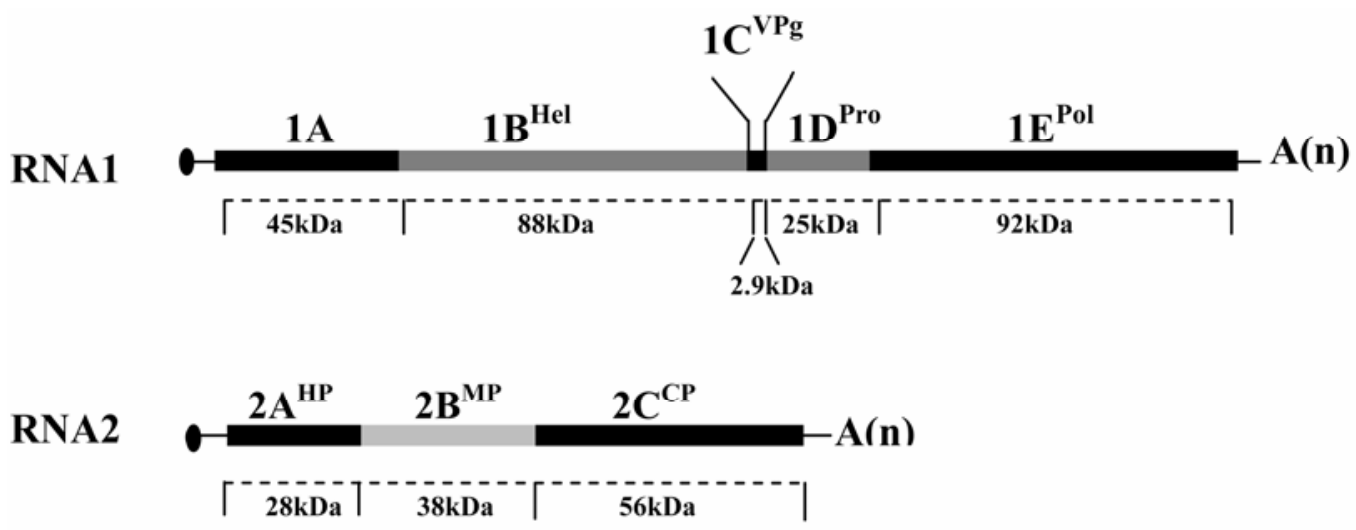

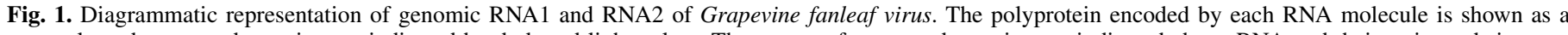

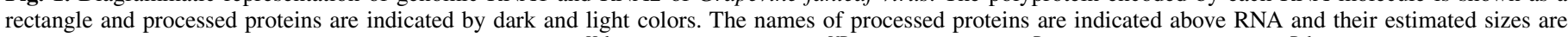

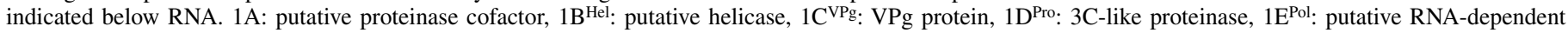

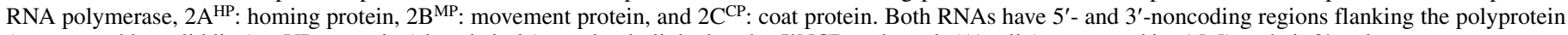
(represented by solid line), a VPg protein (closed circle) covalently linked to the 5' NCR and a poly(A) tail (represented by A[n]) at their $3^{\prime}$ end.. 
PCR products were ligated into the pCR2.1-TOPO vector for cloning and sequencing, and derived sequences were edited as described above.

Phylogenetic analysis. Multiple sequence alignments of RNA1 and RNA2 of GFLV, GDefV, and ArMV (Table 1) were performed with ClustalW (50) and nucleotide and amino acid sequence identity levels were calculated using Vector NTI Advance 11 program (Invitrogen Corp.). The phylogenetic analysis was performed using the neighbor-joining (NJ) method in the MEGA4 analysis package (49). A bootstrap value for each node of $\mathrm{NJ}$ trees was calculated using 1,000 bootstrap replicates and a consensus tree was displayed by TREEVIEW (35).

Recombination analysis. RNA1 and RNA2 sequences were assessed for the occurrence of putative recombination events using Recombination Detection Program version 3 (RDP3) Beta 27 (29) with default parameters (highest acceptable probability value $=0.05)$. The RDP3 package uses a suite of programs to detect the occurrence of robust recombination events (39) namely, RDP (28), GENECONV (34), BOOTSCAN (29), MAXCHI (48), CHIMAERA (38), 3SEQ (5), SISCAN (16), and LARD (18). BOOTSCAN, RDP, and SISCAN are phylogenetic methods; GENECONV, MAXCHI, CHIMAERA, and LARD are substitution methods; and PHYLPRO is a distance comparison method. Recombination sites identified by four or more programs and two or more types of methods were considered to be "significant recombination events" and those detected by fewer than four were considered as "tentative recombination events" (33).

Mapping the spatial distribution of GFLV-infected grapevines. The spatial distribution of GFLV-infected grapevines was assessed in cv. Chardonnay and Pinot Noir blocks. In both blocks, random sampling in different rows was carried out to represent the entire block. Initially, a composite sampling strategy was adopted in such a way that leaf samples from four adjacent grapevines along the row were collected, pooled, and tested by enzyme-linked immunosorbent assay (ELISA) using antibodies specific to GFLV (BIOREBA AG). When a composite sample derived from four adjacent grapevines was tested positive for GFLV, leaf samples were collected again from individual grapevines and retested by ELISA to identify virus-positive grapevines among the group of four. The ELISA results were further confirmed by RTPCR assay as described above.

\section{RESULTS}

Documentation of GFLV in wine grape cultivars. In total, $\approx 1,700$ samples collected from individual grapevines of four wine grape cultivars (Cabernet Franc, Merlot, Pinot Noir, and Chardonnay) were tested by ELISA and RT-PCR for the presence of GFLV. A 322-bp fragment specific to a portion of GFLV CP was amplified in 34/792, 25/801, 4/50, and 2/42 samples from Chardonnay, Pinot Noir, Cabernet Franc, and Merlot, respectively. These results were also confirmed by ELISA using antibodies specific to GFLV. In addition, GFLV-positive samples were tested for other grapevine-infecting viruses by RT-PCR using speciesspecific primers. The results indicated the presence of Grapevine leafroll-associated virus-1 (GLRaV-1), GLRaV-3, Grapevine virus A (GVA), or Grapevine rupestris stem pitting-associated virus (GRSPaV) with GFLV as mixed infection in cv. Chardonnay; GLRaV-1, -2, -3, -4, -5, or GVA with GFLV as mixed infection in cv. Pinot Noir; and GRSPaV as mixed infection in cv. Cabernet Franc (data not shown). In contrast, cv. Merlot tested negative for these viruses, indicating GFLV as a possible single virus infection in this cultivar. Because all four cultivars were planted in different years and in geographically separate vine-

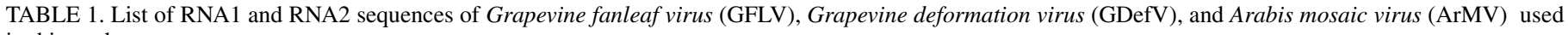
in this study

\begin{tabular}{|c|c|c|c|c|c|c|c|c|c|}
\hline Virus & Genome & Accession & Host & Cultivar & Isolate $^{\mathrm{a}}$ & Size (nt) & Sequence $^{b}$ & $\begin{array}{l}\text { Country } \\
\text { of origin }\end{array}$ & Reference \\
\hline GFLV & RNA1 & GQ332372 & Vitis vinifera & Pinot Noir & WAPN173 & 7,341 & Full length & United States & This study \\
\hline GFLV & RNA1 & GQ332373 & $V$. vinifera & Pinot Noir & WAPN6132 & 7,342 & Full length & United States & This study \\
\hline GFLV & RNA1 & NC_003615 & $V$. vinifera & Muscat & F13 & 7,342 & Full length & France & 43 \\
\hline ArMV & RNA1 & EU617326 & Ligustrum vulgare & $\ldots$ & Lv & 7,334 & Full length & Germany & 11 \\
\hline ArMV & RNA1 & AY303786 & V. vinifera & Pinot gris & NW & 7,334 & Full length & Germany & 56 \\
\hline GFLV & RNA2 & GQ332364 & $V$. vinifera & Chardonnay & WACH911 & 3,753 & Full length & United States & This study \\
\hline GFLV & RNA2 & GQ332367 & $V$. vinifera & Pinot Noir & WAPN57 & 3,778 & Full length & United States & This study \\
\hline GFLV & RNA2 & GQ332368 & $V$. vinifera & Pinot Noir & WAPN173 & 3,778 & Full length & United States & This study \\
\hline GFLV & RNA2 & GQ332369 & V. vinifera & Pinot Noir & WAPN8133 & 3,778 & Full length & United States & This study \\
\hline GFLV & RNA2 & GQ332365 & $V$. vinifera & Pinot Noir & WAPN165 & 3,753 & Full length & United States & This study \\
\hline GFLV & RNA2 & GQ332366 & $V$. vinifera & Pinot Noir & WAPN6132 & 3,753 & Full length & United States & This study \\
\hline GFLV & RNA2 & GQ332370 & $V$. vinifera & Merlot & WAME1492 & 3,773 & Full length & United States & This study \\
\hline GFLV & RNA2 & GQ332371 & $V$. vinifera & Cabernet Franc & WACF2142 & 3,767 & Full length & United States & This study \\
\hline GFLV & RNA2 & NC_003623 & $V$. vinifera & Muscat & F13 & 3,774 & Full length & France & 47 \\
\hline GFLV & RNA2 & EF426852 & $V$. vinifera & Gloria Hungariae & $\mathrm{GHu}$ & 3,806 & Full length & Hungary & 53 \\
\hline GFLV & RNA2 & AY017338 & $V$. vinifera & Huxel & $\mathrm{NW}$ & 3,775 & Full length & Germany & 56 \\
\hline GFLV & RNA2 & AY780899 & $V$. vinifera & Chardonnay & $\mathrm{A} 17 \mathrm{a}$ & 3,333 & Complete & France & 51 \\
\hline GFLV & RNA2 & AY780900 & $V$. vinifera & Chardonnay & $\mathrm{A} 17 \mathrm{~b}$ & 3,333 & Complete & France & 51 \\
\hline GFLV & RNA2 & AY780901 & $V$. vinifera & Chardonnay & $\mathrm{A} 17 \mathrm{~d}$ & 3,324 & Complete & France & 51 \\
\hline GFLV & RNA2 & AY780903 & $V$. vinifera & Chardonnay & B19a & 3,333 & Complete & France & 51 \\
\hline GFLV & RNA2 & AY780902 & $V$. vinifera & Chardonnay & A10a & 3,333 & Complete & France & 51 \\
\hline GFLV & RNA2 & DQ922653-79 & $V$. vinifera & Volovnik & $*$ & $3,330-3,333$ & Complete & Slovenia & 37 \\
\hline GDefV & RNA2 & AY291208 & $V$. vinifera & Dimrit & N66 & 3,753 & Full length & Turkey & 15 \\
\hline ArMV & RNA2 & X81815 & $V$. vinifera & Syrah & $\mathrm{P} 2-\mathrm{U}$ & 3,711 & Full length & Bulgaria & 25 \\
\hline ArMV & RNA2 & X81814 & $V$. vinifera & Syrah & P2-L & 3,852 & Full length & Bulgaria & 25 \\
\hline ArMV & RNA2 & AB279740 & Narcissus & $\ldots$ & $\mathrm{Na}$ & 3,709 & Full length & Japan & 20 \\
\hline ArMV & RNA2 & AB279741 & Lilium sp. & Casablanca & $\mathrm{Li}$ & 3,707 & Full length & Japan & 20 \\
\hline ArMV & RNA2 & EU617327 & Ligustrum vulgare & $\ldots$ & Lv & 3,812 & Full length & Germany & 11 \\
\hline ArMV & RNA2 & AY017339 & V. vinifera & Pinot gris & NW & 3,820 & Full length & Germany & 56 \\
\hline ArMV & RNA2 & EF426853 & $V$. vinifera & Tannat & $\mathrm{Ta}$ & 3,780 & Full length & France & 53 \\
\hline ArMV & RNA2 & AB279739 & Petasites hybridus & Butterbur & $\mathrm{Bu}$ & 3,789 & Full length & Japan & 20 \\
\hline
\end{tabular}

$\mathrm{a} *=$ Vol45c1, Vol47c1, Vol47c2, Vol47c3, Vol47c4, Vol47c5, Vol49c1, Vol49c2, Vol50c1, Vol50c2, Vol51c1, Vol51c2, Vol51c3, Vol51c4, Vol51c5, Vol52c1, Vol54c1, Vol54c2, Vol54c3, Vol55c1, Vol55c1, Vol55c2, Vol55c3, Vol57c1, Vol57c2, Vol57c3, Vol57c4, Vol57c5, and Vol57c6.

${ }^{\mathrm{b}}$ Full length = entire genome segment; Complete = complete open reading frame. 
yards by unrelated growers, the results indicated independent introductions of GFLV-infected planting materials into these vineyards. Typical symptoms of GFLV such as leaf deformation, vein banding, and yellow mosaic symptoms were observed in cvs. Pinot Noir and Chardonnay (Supplementary Figure). No such symptoms were observed in GFLV-positive grapevines of cvs. Merlot and Cabernet Franc.

Spatial distribution of GFLV-infected grapevines. Under field conditions, GFLV is transmitted by the viruliferous $X$. index (17). Clustering or "patchiness" of symptomatic grapevines in a vineyard block would indicate vine-to-vine spread of the virus by the nematode vector. In order to assess the field spread of GFLV, spatial distribution of virus-infected grapevines was assessed in cvs. Chardonnay and Pinot Noir that had a higher percentage of virus-infected grapevines. Because these cultivars were planted in 1960 and 1982, respectively, vine-to-vine spread of GFLV by resident nematodes would have occurred due to the growth of grapevines for a long period of time. The data showed random distribution of GFLV-positive grapevines in both blocks. In some rows, two to four adjacent grapevines tested positive for the virus. The random distribution of virus-infected grapevines was further confirmed by aggregation analysis of the spatial distribution of infected plants in the two blocks (data not shown). Preliminary analysis of soil samples collected around GFLV-positive grapevines showed the presence of $X$. pachtaicum but not $X$. index. In preliminary studies, groups of $X$. pachticum tested negative for GFLV by RT-PCR, indicating the absence of virus in these nematodes (data not shown). These results suggested spread of GFLV through virus-infected planting materials. The presence of virus in neighboring grapevines could be the result of adjacent planting of cuttings sourced from a virus-infected grapevine.

Analysis of RNA1 and RNA2 sequences of GFLV isolates. In total, two RNA1 and eight RNA2 sequences were obtained from four wine grape cultivars (Table 1). These sequences were compared with corresponding sequences of GFLV, ArMV, and GDefV available in GenBank.

The RNA1 of two GFLV isolates, WAPN173 and WAPN6132, from cv. Pinot Noir is composed of 7,341 and 7,342 nt, respectively (Table 1), respectively, excluding poly $(\mathrm{A})$ tail. The difference in size was due to a single nucleotide deletion in the $3^{\prime}$ noncoding region (NCR) of isolate WAPN173. Both isolates had $89 \%$ nucleotide sequence identity between them and 87 to $89 \%$ with RNA1 of strain F13. The two isolates showed genome organization similar to that reported for GFLV strain F13 from France $(44,56)$. The P1 polyprotein of isolates WAPN173 and WAPN6132 showed 90 and $87 \%$ identity at the nucleotide level and 92 and $93 \%$ identity (96\% similarity) at the amino acid level, respectively, with that of strain F13.

The RNA2 of GFLV isolates from Washington had genome organization similar to F13, NW, and GHu $(26,47,53,57)$. However, the size of RNA2, excluding polyA tail, varied among these isolates between 3,753 and 3,776 nt (Table 1). In pairwise comparisons, RNA2 of Washington isolates showed nucleotide sequence identities of 85 to $99 \%$ between them; 81 to $92 \%$ with F13, NW, and GHu isolates of GFLV; 72 to $74 \%$ with GDefV; and 66 to $72 \%$ with different isolates of ArMV. These results suggested that GFLV isolates from Washington are more closely related to GFLV than to other subgroup A nepoviruses.

The size of P2 polyprotein of GFLV isolates from Washington was 3,327 to $3,333 \mathrm{nt}$ encoding a polyprotein of 1,108 to 1,110 amino acids (aa). This variation was due to differences in the size of $2 \mathrm{~A}^{\mathrm{HP}}$ (256 to $258 \mathrm{aa}$ ), whereas $2 \mathrm{~B}^{\mathrm{MP}}$ and $2 \mathrm{C}^{\mathrm{CP}}$ were 348 and 504 aa, respectively, in size among all isolates. It is noteworthy that $2 \mathrm{~A}^{\mathrm{HP}}$ of strain F13 from France (47) was shorter by 1 aa than the other isolates, due to a deletion of 3 nt between nucleotides 262 and 266. A deletion of 3 nt between 299 and 303 in isolates Vol51C3, Vol51C5, Vol52C1, Vol54C2, Vol55C1, and Vol57C5 and between 344 and 348 in isolate Vol54C3 from Slovenia (37) and a 9-nt deletion between 300 and 304, 305 and 309, and 319 and 321 in isolate A17d from France (52) was also reported.

A pairwise comparison of $\mathrm{P} 2$ polyprotein of Washington isolates showed higher nucleotide and amino acid sequence identities with other GFLV isolates than with corresponding sequences of GDefV and ArMV (Table 2). Based on these results, isolates WACH911, WAPN165, and WAPN6132 clustered as one group and isolates WAPN57, WAPN173, and WAPN8133 clustered as the second group. Isolates WAME1492 and WACF2142 showed lower nucleotide sequence identity with these six isolates but higher amino acid sequence identity with isolates WAPN57, WAPN173, and WAPN8133. These results indicated the presence of two distinct groups of GFLV variants in Washington vineyards. Among the six, isolates WACH911, WAPN165, and WAPN6132 showed lower sequence identities with GFLV isolates from other countries. The $2 \mathrm{~A}^{\mathrm{HP}}$ was more diverse, with three Washington isolates (WACH911, WAPN165, and WAPN6132) showing higher nucleotide ( 84 to $85 \%$ ) and amino acid (83 to $85 \%$ ) sequence identities with the corresponding sequence of GDefV than with GFLV and ArMV. The $2 \mathrm{~A}^{\mathrm{HP}}$ of the other five isolates (WAPN57, WAPN173, WAPN8133, WAME1492, and WACF2142) showed higher identity values ( 85 to $92 \%$ ) with GFLV than with ArMV and GDefV. These results indicated that the $2 \mathrm{~A}^{\mathrm{HP}}$ of isolates WACH911, WAPN165, and WAPN6132 are more closely related to GDefV than GFLV, suggesting possible interspecies recombination between these GFLV isolates and GDefV. The $2 \mathrm{~B}^{\mathrm{MP}}$ sequences of Washington isolates showed 78 and $93 \%$ identity at the nucleotide level and 88 and $100 \%$ identity at the amino acid level between them and with corresponding sequences of other GFLV isolates, and lower identities with GDefV and ArMV. The $2 \mathrm{C}^{\mathrm{CP}}$ sequences of Washington isolates showed 86 and $91 \%$ identity at the nucleotide level and 93 and $99 \%$ identity at the amino acid level between them and with corresponding sequences of other GFLV isolates and lower identities with GDefV and ArMV.

Analysis of 5' and 3' NCRs of RNA1 and RNA2. The 5' NCR of RNA1 of isolates WAPN173 and WAPN6132 was 242 nt in length, with $82 \%$ sequence identity between them and 83 to $85 \%$ identity with the corresponding sequence of isolate F13. The 3' NCR of RNA1 of isolates WAPN173 and WAPN6132 was 244 and $245 \mathrm{nt}$, respectively, with $92 \%$ sequence identity between them and 88 to $89 \%$ identity with the corresponding sequence of isolate F13. The 5' NCR of RNA2 was variable in size, with three isolates (WACH911, WAPN165, and WAPN6132) having $211 \mathrm{nt}$, two (WAME1492 and WACF2142) having $228 \mathrm{nt}$, and three (WAPN57, WAPN173, and WAPN8133) having $231 \mathrm{nt}$. Unlike the 5' NCR sequences, the $3^{\prime}$ NCRs of RNA2 were identical in size (212 nt) and showed 83 to $97 \%$ sequence identities between them and 84 to $92 \%$ identity with the corresponding sequence of other GFLV isolates.

The first seven nucleotides (ATGAAAA) at the $5^{\prime}$ NCR were conserved in both RNA1 and RNA2 of all GFLV isolates (Fig. 2). These sequences were also conserved in RNA2 of GDefV and in both RNAs of ArMV available to date, with the exception of RNA2 of ArMV isolate Butterbur, which contains the sequence 5'-ATGTTAAAA. Although the 5' NCRs of RNA1 and RNA2 of GFLV, ArMV, and GDefV are distinct, three conserved putative stem-loop structures are common among them (Fig. 2). The motif 1 and 3 were conserved in RNA1 and RNA2 of all viruses. Motif 2 was conserved in all isolates of GFLV and RNA2 of GDefV and is distinct in ArMV. Motif 2 was absent in RNA2 of GFLV isolates WACH911, WAPN165, and WAPN6132 due to a 17-nt deletion in the $5^{\prime} \mathrm{NCR}$. It is interesting to note that motif 2 present in the recombinant isolate GFLV-RNA2-GHu was similar to that of ArMV and motif 2 present in ArMV-RNA2 of isolate Butterbur was similar to that of GFLV.

Phylogenetic analysis of GFLV isolates. Phylogenetic analysis of the RNA2-encoded open reading frame of eight isolates of GFLV from Washington along with corresponding sequences of 
GFLV, ArMV, and GDefV available to date was carried out to gain further insights into their evolutionary relationship. In view of the large number of GFLV sequences from Slovenia (37), we included in these analyses sequences from two isolates representing each of the three Slovene groups. Isolates WAPN57, WAPN173, and WAPN8133 clustered together and were close with isolate F13 from France regardless of the gene sequence compared (Fig. 3). In contrast, isolates WAPN165, WAPN6132, and WACH911 showed contrasting phylogenetic relationships depending on the gene sequence compared. These isolates clustered closely with GDefV in a $2 \mathrm{~A}^{\mathrm{HP}}$-based tree (Fig. 3B) but grouped with GFLV isolates mentioned above in $2 \mathrm{~B}^{\mathrm{MP}}$ - and $2 \mathrm{C}^{\mathrm{CP}}$-based trees (Fig. 3C and D). However, WACF2142 and WAME1492 clustered with different GFLV isolates depending on the gene sequence compared. As reported earlier (37), GFLV isolates from Slovenia did not cluster with other GFLV isolates. It is interesting to note that ArMV isolate Butterbur (20) showed clustering with GFLV isolates and GDefV in $2 \mathrm{~A}^{\mathrm{HP}}$-based tree. GFLV isolate GHu from Hungary showed incongruent phylogeny (53), clustering with GFLV isolates in all but the $2 \mathrm{~B}^{\mathrm{MP}}$-based tree, where it clustered with ArMV isolates (Fig. 3C). Phylogenetic incongruence of GFLV isolates from Washington in $2 \mathrm{~A}^{\mathrm{HP}}$ - and $2 \mathrm{~B}^{\mathrm{MP}}$-based trees suggested that their genomic RNA2 originated from recombinant events in different gene sequences between GFLV, GDefV, and ArMV. We did not conduct similar studies for RNA1, because complete RNA1 genomic sequences are available only for three GFLV isolates.

Identification of putative intra- and interspecies recombinations in RNA1 and RNA2 of GFLV isolates. Putative recombination events between GFLV, ArMV, and GDefV were analyzed by using the RDP3 program that implements several recombination-detection methods (29). The locations of recombination break points in five Washington isolates and the putative "parental sequences" are listed in Table 3. The crossover sites were identified at different locations for these recombinant isolates, with eight involving interspecies recombination events in $2 \mathrm{~A}^{\mathrm{HP}}$ and $2 \mathrm{~B}^{\mathrm{MP}}$. The RNA2 genomes of WACH911, WAPN165, and WAPN6132 showed one significant recombination event involving GFLV isolate WAPN57 (major parent) and GDefV (minor parent). Recombination breakpoints in these isolates suggested that they occurred at more or less similar positions in $2 \mathrm{~A}^{\mathrm{HP}}$ sequences. Three significant recombination events were observed in these isolates involving GFLV isolate F13 (major parent) and ArMV isolate Butterbur (minor parent). In these events, the locations of $5^{\prime}$ recombination breakpoints were in more or less similar positions but the $3^{\prime}$ breakpoints were somewhat different in position and the length of the recombination pattern. Interestingly, isolate WACH911 came from cv. Chardonnay and isolates WAPN165 and 6132 came from cv. Pinot Noir in two different vineyard blocks. It is also noteworthy that the two recombinant isolates (WAPN165 and WAPN6132) and three nonrecombinant isolates (WAPN57, WAPN173, and WAPN8133) were from cv. Pinot Noir planted in the same block. However, these isolates came from separate grapevines and we did not find any evidence for mixed infection of these two types of sequences in a single grapevine. In contrast, all GFLV isolates from the Chardonnay block seem to be recombinant isolates, because $2 \mathrm{~A}^{\mathrm{HP}}$ sequences from 10 individual grapevines were identical (data not shown).

Two significant recombination events were identified in the RNA2 genomic sequence of isolate WACF2142 (Table 3). One of them was located in the $2 \mathrm{~A}^{\mathrm{HP}}$ sequence between nucleotides 510 and 656 involving isolates GFLV-F13 (major parent) and ArMVLily (minor parent). The second was located in the $2 \mathrm{~B}^{\mathrm{MP}}$ sequence between nucleotides 1,299 and 1,578 involving GFLV isolate WAPN173 (major parent) and GDefV (minor parent).

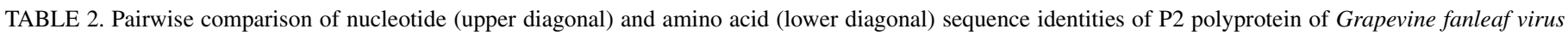

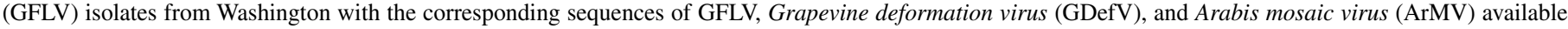
in GenBank ${ }^{\mathrm{a}}$

\begin{tabular}{|c|c|c|c|c|c|c|c|c|c|c|c|c|c|c|c|c|c|c|c|c|c|c|c|c|c|c|c|c|c|c|c|c|c|}
\hline \multicolumn{2}{|c|}{ Virus } & \multirow{2}{*}{$\begin{array}{c}\begin{array}{c}\text { Accession } \\
\text { no. }\end{array} \\
\text { GQ332364 }\end{array}$} & \multirow{2}{*}{$\frac{1}{\ldots}$} & \multirow{2}{*}{$\frac{2}{97}$} & \multirow{2}{*}{$\frac{3}{97}$} & \multirow{2}{*}{$\frac{4}{87}$} & \multirow{2}{*}{$\frac{5}{87}$} & \multirow{2}{*}{$\frac{6}{87}$} & \multirow{2}{*}{$\frac{7}{86}$} & \multirow{2}{*}{$\frac{8}{86}$} & \multirow{2}{*}{$\begin{array}{c}9 \\
81\end{array}$} & \multirow{2}{*}{$\frac{10}{87}$} & & & 13 & 14 & 15 & 16 & 17 & 18 & 19 & 20 & 21 & 22 & 23 & 24 & 25 & 26 & 27 & 28 & 29 & 30 & 31 \\
\hline 1 & GFLV & & & & & & & & & & & & & 86 & 86 & 85 & 86 & 85 & 87 & 87 & 86 & 86 & 86 & 86 & 74 & 66 & 69 & 68 & 69 & 69 & 68 & 69 & 69 \\
\hline 2 & GFLV & GQ332365 & 98 & $\ldots$ & 98 & 87 & 87 & 87 & 86 & 85 & 81 & 86 & 87 & 86 & 86 & 85 & 85 & 85 & 87 & 87 & 85 & 86 & 86 & 86 & 74 & 66 & 68 & 68 & 69 & 69 & 68 & 69 & 68 \\
\hline 3 & GFLV & GQ332366 & 98 & 98 & $\ldots$ & 88 & 87 & 87 & 86 & 85 & 81 & 86 & 88 & 86 & 86 & 86 & 86 & 85 & 87 & 87 & 86 & 86 & 86 & 86 & 74 & 66 & 69 & 68 & 69 & 69 & 68 & 69 & 68 \\
\hline 4 & GFLV & GQ332367 & 90 & 90 & 91 & $\ldots$ & 99 & 99 & 91 & 88 & 84 & 90 & 91 & 90 & 89 & 89 & 90 & 88 & 89 & 89 & 88 & 88 & 90 & 90 & 72 & 67 & 69 & 68 & 69 & 69 & 69 & 72 & 71 \\
\hline 5 & GFLV & GQ332368 & 90 & 91 & 91 & 100 & & 99 & 91 & 88 & 84 & 90 & 91 & 90 & 89 & 89 & 90 & 88 & 90 & 90 & 88 & 88 & 90 & 90 & 72 & 67 & 69 & 68 & 69 & 69 & 69 & 72 & 71 \\
\hline 6 & GFLV & GQ332369 & 90 & 90 & 91 & 99 & 100 & $\ldots$ & 90 & 88 & 84 & 90 & 92 & 90 & 90 & 89 & 90 & 88 & 89 & 89 & 88 & 88 & 90 & 89 & 72 & 67 & 69 & 68 & 69 & 69 & 69 & 72 & 71 \\
\hline 7 & GFLV & GQ332370 & 91 & 91 & 91 & 96 & 96 & 96 & $\ldots$ & 89 & 85 & 90 & 91 & 90 & 89 & 89 & 90 & 88 & 89 & 89 & 88 & 88 & 89 & 89 & 72 & 68 & 70 & 69 & 69 & 70 & 69 & 72 & 72 \\
\hline 8 & GFLV & GQ332371 & 91 & 91 & 91 & 95 & 95 & 95 & 95 & $\ldots$ & 84 & 88 & 89 & 88 & 88 & 89 & 88 & 87 & 88 & 88 & 88 & 88 & 88 & 88 & 72 & 67 & 70 & 69 & 70 & 70 & 70 & 72 & 72 \\
\hline 9 & GFLV & EF426852 & 86 & 86 & 86 & 90 & 91 & 91 & 92 & 91 & $\ldots$ & 85 & 84 & 84 & 84 & 84 & 84 & 84 & 84 & 84 & 85 & 85 & 84 & 84 & 70 & 69 & 72 & 71 & 71 & 72 & 72 & 74 & 74 \\
\hline 10 & GFLV & AY017338 & 91 & 91 & 91 & 96 & 96 & 96 & 97 & 95 & 92 & $\ldots$ & 90 & 90 & 90 & 89 & 90 & 90 & 90 & 90 & 89 & 89 & 90 & 90 & 72 & 68 & 69 & 69 & 69 & 70 & 69 & 72 & 72 \\
\hline 11 & GFLV & NC_003623 & 90 & 90 & 91 & 96 & 96 & 96 & 96 & 94 & 91 & 96 & $\ldots$ & 90 & 90 & 89 & 90 & 90 & 90 & 90 & 88 & 88 & 90 & 90 & 72 & 68 & 69 & 69 & 69 & 69 & 69 & 71 & 71 \\
\hline 12 & GFLV & AY780899 & 90 & 90 & 91 & 95 & 95 & 95 & 95 & 94 & 90 & 95 & 94 & $\ldots$ & 94 & 90 & 98 & 91 & 89 & 89 & 88 & 88 & 89 & 89 & 72 & 67 & 68 & 68 & 69 & 69 & 69 & 71 & 71 \\
\hline 13 & GFLV & AY780900 & 91 & 91 & 91 & 95 & 95 & 95 & 96 & 94 & 91 & 96 & 95 & 96 & $\ldots$ & 89 & 94 & 93 & 89 & 89 & 88 & 89 & 89 & 89 & 72 & 68 & 69 & 68 & 69 & 70 & 69 & 72 & 71 \\
\hline 14 & GFLV & AY780901 & 90 & 90 & 90 & 94 & 94 & 94 & 95 & 95 & 90 & 95 & 94 & 95 & 95 & $\ldots$ & 89 & 88 & 88 & 88 & 87 & 87 & 88 & 88 & 72 & 67 & 69 & 69 & 69 & 70 & 69 & 72 & 72 \\
\hline 15 & GFLV & AY780902 & 90 & 91 & 91 & 96 & 96 & 95 & 96 & 94 & 91 & 96 & 95 & 98 & 96 & 95 & $\ldots$ & 91 & 89 & 89 & 88 & 88 & 89 & 89 & 72 & 68 & 69 & 68 & 69 & 70 & 69 & 71 & 71 \\
\hline 16 & GFLV & AY780903 & 91 & 91 & 91 & 95 & 95 & 95 & 95 & 95 & 90 & 96 & 95 & 94 & 95 & 94 & 95 & $\ldots$ & 88 & 88 & 89 & 89 & 88 & 88 & 72 & 68 & 69 & 68 & 69 & 69 & 69 & 72 & 71 \\
\hline 17 & GFLV & DQ922656 & 91 & 91 & 91 & 95 & 95 & 95 & 95 & 94 & 90 & 96 & 95 & 94 & 95 & 94 & 94 & 94 & $\ldots$ & 99 & 89 & 89 & 98 & 98 & 72 & 68 & 70 & 69 & 70 & 70 & 70 & 72 & 72 \\
\hline 18 & GFLV & DQ922661 & 92 & 92 & 92 & 95 & 95 & 95 & 96 & 95 & 91 & 96 & 96 & 94 & 96 & 94 & 95 & 95 & 100 & $\ldots$ & 89 & 89 & 98 & 98 & 72 & 68 & 70 & 69 & 70 & 70 & 70 & 72 & 72 \\
\hline 19 & GFLV & DQ922666 & 90 & 90 & 90 & 94 & 94 & 94 & 95 & 94 & 91 & 95 & 94 & 94 & 94 & 94 & 94 & 94 & 95 & 95 & $\ldots$ & 99 & 88 & 88 & 72 & 68 & 70 & 69 & 70 & 70 & 70 & 73 & 72 \\
\hline 20 & GFLV & DQ922667 & 90 & 90 & 91 & 94 & 94 & 94 & 95 & 94 & 92 & 95 & 94 & 94 & 94 & 94 & 95 & 94 & 95 & 95 & 99 & $\ldots$ & 88 & 88 & 72 & 68 & 70 & 69 & 70 & 70 & 70 & 72 & 72 \\
\hline 21 & GFLV & DQ922670 & 90 & 91 & 90 & 95 & 95 & 95 & 95 & 94 & 90 & 96 & 95 & 94 & 95 & 94 & 94 & 94 & 98 & 98 & 94 & 94 & $\ldots$ & 99 & 72 & 68 & 70 & 68 & 70 & 69 & 69 & 72 & 72 \\
\hline 22 & GFLV & DQ922679 & 90 & 90 & 90 & 94 & 95 & 94 & 95 & 94 & 90 & 95 & 95 & 94 & 95 & 94 & 94 & 94 & 97 & 97 & 93 & 94 & 98 & $\ldots$ & 72 & 67 & 69 & 68 & 70 & 69 & 69 & 72 & 72 \\
\hline 23 & GDefV & AY291208 & 76 & 76 & 76 & 74 & 74 & 73 & 73 & 73 & 71 & 74 & 73 & 73 & 74 & 73 & 73 & 73 & 73 & 73 & 74 & 74 & 73 & 73 & $\ldots$ & 68 & 70 & 70 & 70 & 70 & 70 & 71 & 71 \\
\hline 24 & ArMV & AB279739 & 68 & 68 & 68 & 69 & 69 & 69 & 69 & 69 & 71 & 70 & 69 & 68 & 69 & 68 & 69 & 68 & 69 & 69 & 69 & 69 & 68 & 69 & 69 & $\ldots$ & 71 & 70 & 70 & 70 & 71 & 72 & 71 \\
\hline 25 & ArMV & AB279740 & 71 & 72 & 72 & 72 & 72 & 72 & 71 & 73 & 74 & 72 & 71 & 71 & 71 & 72 & 72 & 72 & 72 & 72 & 72 & 71 & 72 & 72 & 74 & 73 & $\cdots$ & 91 & 88 & 84 & 86 & 86 & 84 \\
\hline 26 & ArMV & AB279741 & 71 & 72 & 72 & 71 & 71 & 71 & 71 & 72 & 73 & 72 & 71 & 70 & 71 & 71 & 71 & 71 & 71 & 71 & 71 & 71 & 71 & 71 & 74 & 73 & 95 & $\ldots$ & 87 & 84 & 86 & 86 & 83 \\
\hline 27 & ArMV & EU617327 & 71 & 72 & 72 & 72 & 72 & 72 & 72 & 73 & 74 & 72 & 72 & 71 & 71 & 72 & 72 & 71 & 72 & 72 & 72 & 72 & 71 & 71 & 74 & 74 & 91 & 91 & $\ldots$ & 87 & 86 & 86 & 83 \\
\hline 28 & ArMV & X81814 & 71 & 72 & 72 & 73 & 73 & 72 & 72 & 73 & 75 & 73 & 73 & 72 & 72 & 73 & 72 & 72 & 72 & 72 & 73 & 73 & 72 & 72 & 73 & 74 & 88 & 89 & 93 & $\ldots$ & 89 & 84 & 82 \\
\hline 29 & ArMV & X81815 & 71 & 72 & 72 & 71 & 71 & 71 & 71 & 72 & 74 & 72 & 71 & 71 & 71 & 72 & 71 & 71 & 71 & 71 & 72 & 72 & 71 & 71 & 74 & 73 & 91 & 91 & 90 & 91 & $\ldots$ & 86 & 83 \\
\hline 30 & ArMV & AY017339 & 73 & 73 & 73 & 76 & 76 & 76 & 76 & 77 & 79 & 77 & 76 & 75 & 75 & 76 & 76 & 75 & 76 & 76 & 76 & 76 & 76 & 76 & 75 & 76 & 89 & 90 & 91 & 88 & 90 & $\ldots$ & 86 \\
\hline 31 & ArMV & EF426853 & 72 & 73 & 73 & 76 & 76 & 76 & 76 & 77 & 79 & 76 & 76 & 75 & 76 & 76 & 76 & 75 & 76 & 76 & 76 & 76 & 76 & 75 & 74 & 75 & 88 & 89 & 90 & 88 & 89 & 94 & $\ldots-$ \\
\hline
\end{tabular}

a Sequence identity values between Washington isolates are in bold with gray background and values with other GFLV isolates are in bold. 
Significant intraspecies recombination events were also detected in RNA1 and RNA2 sequences of GFLV isolates. One such event was detected in RNA1 of GFLV isolate WAPN173 between nucleotides 825 and 1,648 involving GFLV isolates F-13 (major parent) and WAPN6132 (minor parent). Another putative event was detected in the 5' NCR of RNA2 of isolate WACF2142 between nucleotides 1 and 298 involving GFLV-NW (major parent) and WAME1492 (minor parent).

\section{DISCUSSION}

In this study, we analyzed genetic diversity of GFLV isolates recovered from four wine grape cultivars. Four of the eight isolates showed significant interspecies recombination events in RNA2 involving sequences from GDefV and ArMV (Table 3). In a recent report (53), two interspecies recombinant isolates, GFLV$\mathrm{GHu}$ (19) and ArMV-Ta (23) from Vitis vinifera cvs. Gloriae Hungariae and Tannatthe, respectively, were characterized. GFLV$\mathrm{GHu}$ was found to contain sequences of ArMV in the 5' NCR, $2 \mathrm{~A}^{\mathrm{HP}}$ and $2 \mathrm{~B}^{\mathrm{MP}}$ proteins, and ArMV-Ta was found to contain sequences of GFLV in the $2 \mathrm{~B}^{\mathrm{MP}}$ protein. Our studies on molecular characterization of GFLV field isolates from $V$. vinifera cvs.
Cabernet Franc, Pinot Noir, Merlot, and Chardonnay provided new evidence of interspecies recombination events between GFLV, ArMV, and GDefV in other portions of $2 \mathrm{~A}^{\mathrm{HP}}$ and $2 \mathrm{~B}^{\mathrm{MP}}$ genes. In addition, one of the GFLV isolates (WACF2142) showed putative recombination events in $2 \mathrm{~A}^{\mathrm{HP}}$ and $2 \mathrm{~B}^{\mathrm{MP}}$ genes involving two different nepoviruses, ArMV and GDefV, respectively. Previously, GFLV-GFLV recombination events in RNA2 have been documented in Slovenia (37), Tunisia (6) and France $(51,52,54)$. Results from this study indicated that such events could occur in both RNA1 and RNA2 of GFLV field isolates.

Based on the results reported here and elsewhere (53), the $5^{\prime}$ $\mathrm{NCR}, 2 \mathrm{~A}^{\mathrm{HP}}$ and $2 \mathrm{~B}^{\mathrm{MP}}$ sequences seem to be "hot spots" for interspecies genetic exchanges between closely related grapevineinfecting nepoviruses. However, the locations of recombination breakpoints are different in the recombinant isolates reported in this study (Table 3), indicating that the patterns of sequence exchange among GFLV, ArMV, and GDefV are likely to occur randomly. Nevertheless, the sequence exchanges in $2 \mathrm{~A}^{\mathrm{HP}}$ and $2 \mathrm{~B}^{\mathrm{MP}}$ proteins were in-frame, which would be expected in order to yield a full-length polyprotein for processing to give functional proteins. Recombination in a nonstructural protein (gene $2 \mathrm{~B}^{\mathrm{MP}}$ ) between Grapevine chrome mosaic virus and Tomato black ring
ArMV-RNA2 - Na ArMV-RNA2 - P2 - L ArMV-RNA2 - Li ArMV-RNA2 - P2 -U ArMV-RNA2 - NW ArMV-RNA2 - Ta ArMV-RNA2-Bu ArMV-RNA2 - L ArMV-RNA1 - LV ArMV-RNA1 - NW GFLV-RNA2 - WAPN165 GFLV-RNA2 -WAPN6132 GFLV-RNA2 - WACH 911 GFLV-RNA2 - WAME14 92 GFLV-RNA2 - WACF2 142 GFLV-RNA2 - NW GFLV-RNA2 - F13 GFLV-RNA2 -WAPN173 GFLV-RNA2 -WAPN8133 GFLV-RNA2 - WAPN 57 GFLV-RNA2 - GHu GFLV-RNA1 - WAPN173 GFLV-RNA1-WAPN6132 GFLV-RNA1 - F13 GDefV-RNA2

ArMV-RNA2 - Na
ArMV-RNA2 - P2 - L
ArMV-RNA2 - Li
ArMV-RNA2 - P2 -U
ArMV-RNA2 -NW
ArMV-RNA2 - Ta
ArMV-RNA2 - Bu
ArMV-RNA2 - LV
ArMV-RNA1 - LV
ArMV-RNA1 - NW
GFLV-RNA2 - WAPN165
GFLV-RNA2 - WAPN6132
GFLV-RNA2 - WACH911
GFLV-RNA2 - WAME1492
GFLV-RNA2 - WACF2142
GFLV-RNA2 - NW
GFLV-RNA2 - F13
GFLV-RNA2 - WAPN173
GFLV-RNA2 - WAPN8133
GFLV-RNA2 - WAPN57
GFLV-RNA2 - GHU
GFLV-RNA1 - WAPN173
GFLV-RNA1 - WAPN6132
GFLV-RNA1 - F13
GDE f - RNA2

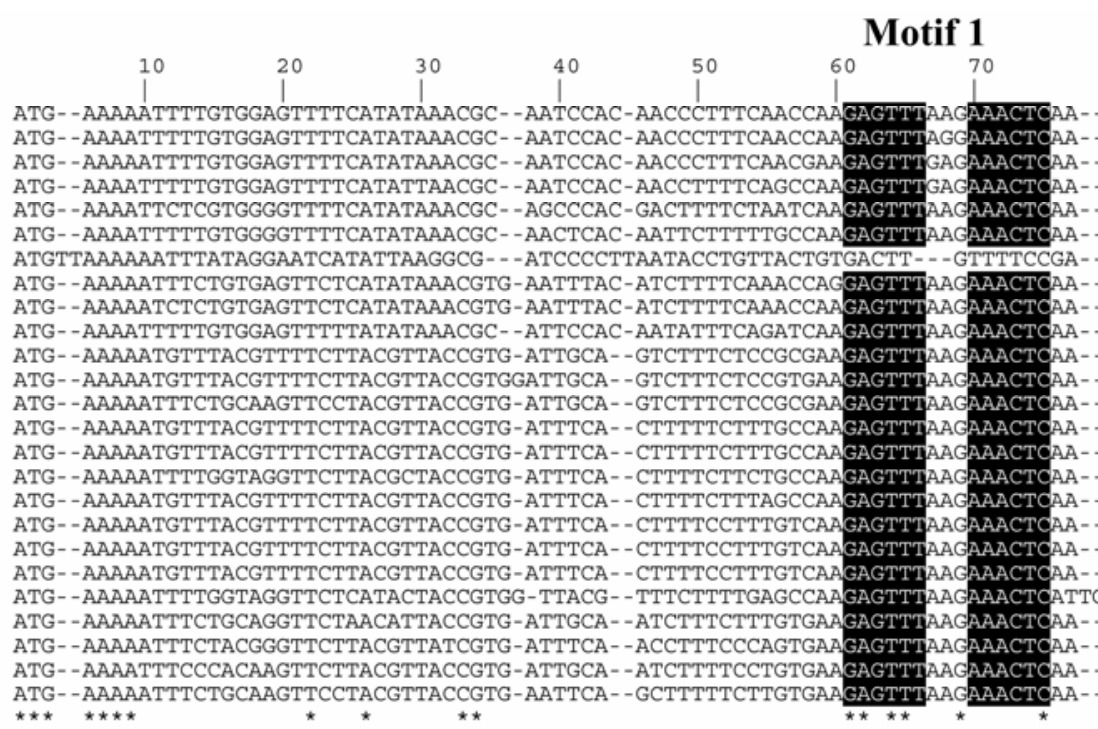

80

\begin{abstract}
90
\end{abstract}
100

110 -AATTGTTCTTTGCCAATCCGTTAAGAGCG AATTGTTTACAATCAATCCGTTAAGAGCG AATTGTTCTTTGTCAATCCGTTAAGAGCG AATTGTTCTTTGTCAATCCGTTAAGAGCG AATTTGTTCGAGTCAATCCGTTAAGAGCG GTTTGAT-ATAGCCAATCCGTTAAGAGCG -GTTTGTCCATTTTAAGTCCGTCATAAGCG AATTGTTCTTTGCCAATCCGTTAAGAGCG AATTGTTCTTTGCCAATCCGTTAAGAGCG AATTGTT-ACAATCAATCCGTTAAGAGCG -AATTGTT-ACAATCAATCCGTTAAGAGCG -GATTG -GATTG -AATTG -AAGTG AAGTG AAGTG AAGTG -AAGTG AAGTG AGCG GATTG GATTG GATTG - AGTT $\begin{array}{ll}\text { Motif } 2 & \text { Motif } 3\end{array}$

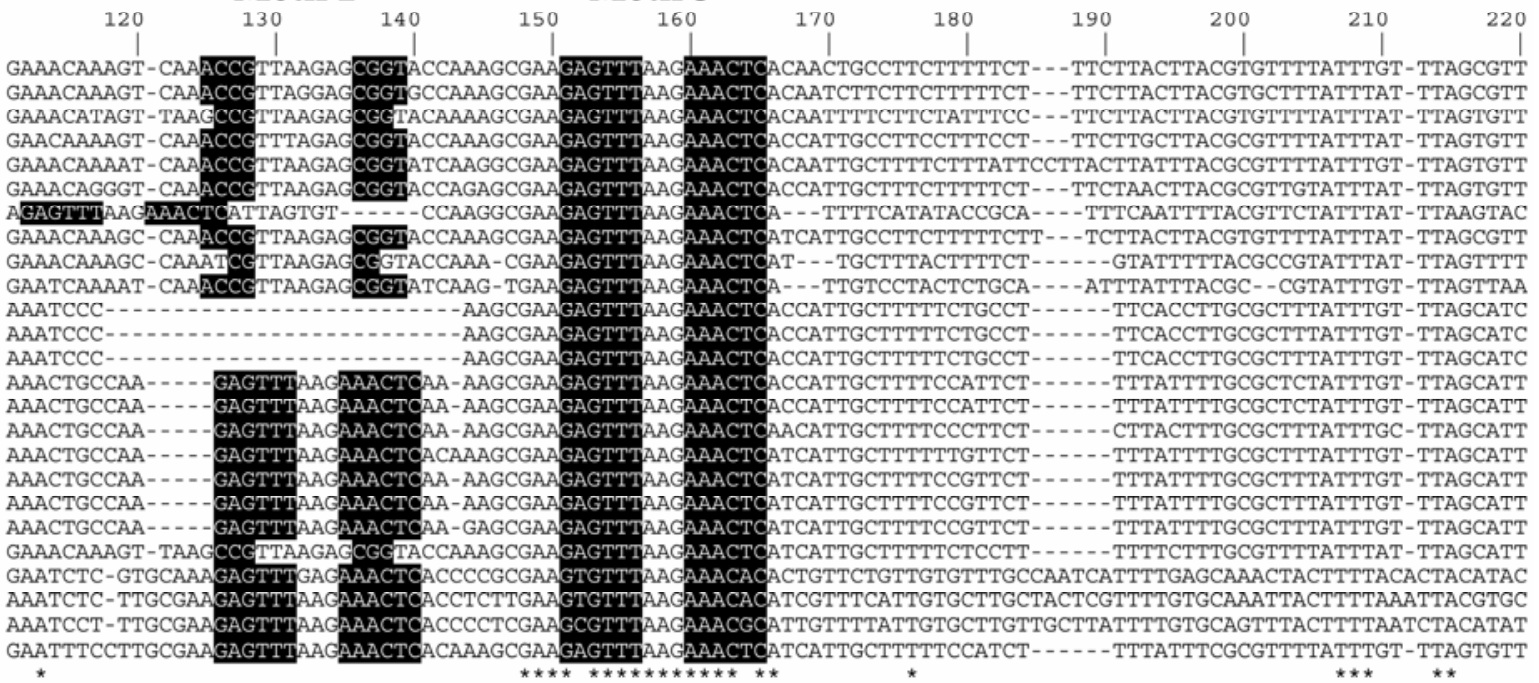

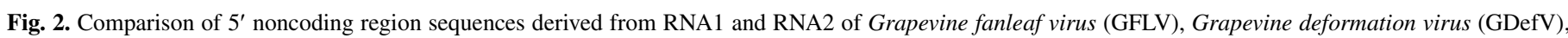

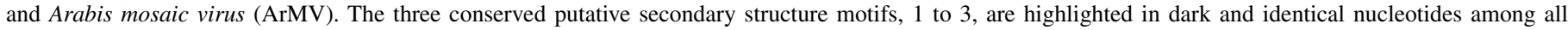

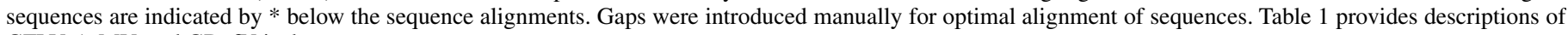
GFLV, ArMV, and GDefV isolates. 
virus, two nepoviruses in subgroup B, has also been reported (22), further suggesting that the observed recombination events in nonstructural proteins of GFLV are less disruptive or nonlethal and could result in the emergence of genetically stable chimeric viruses when two closely related nepoviruses co-infect a compatible host. Such viable recombinants can play a role in the evolution of GFLV (14). It is possible that the observed recombination events can occur during synthesis of the negative or positive strand of the viral genome. The presence of two distinct breakpoints in each of the recombination events (Table 3) implies two template switches, and replicase-driven template-switching has been proposed as a possible mechanism of recombination in several viruses (31), including GFLV $(52,53)$.

An analysis of the 5' NCR of both RNAs revealed three conserved motifs with predicted stem-loop structures (Fig. 2). However, only motifs 1 and 3 are conserved among all GFLV
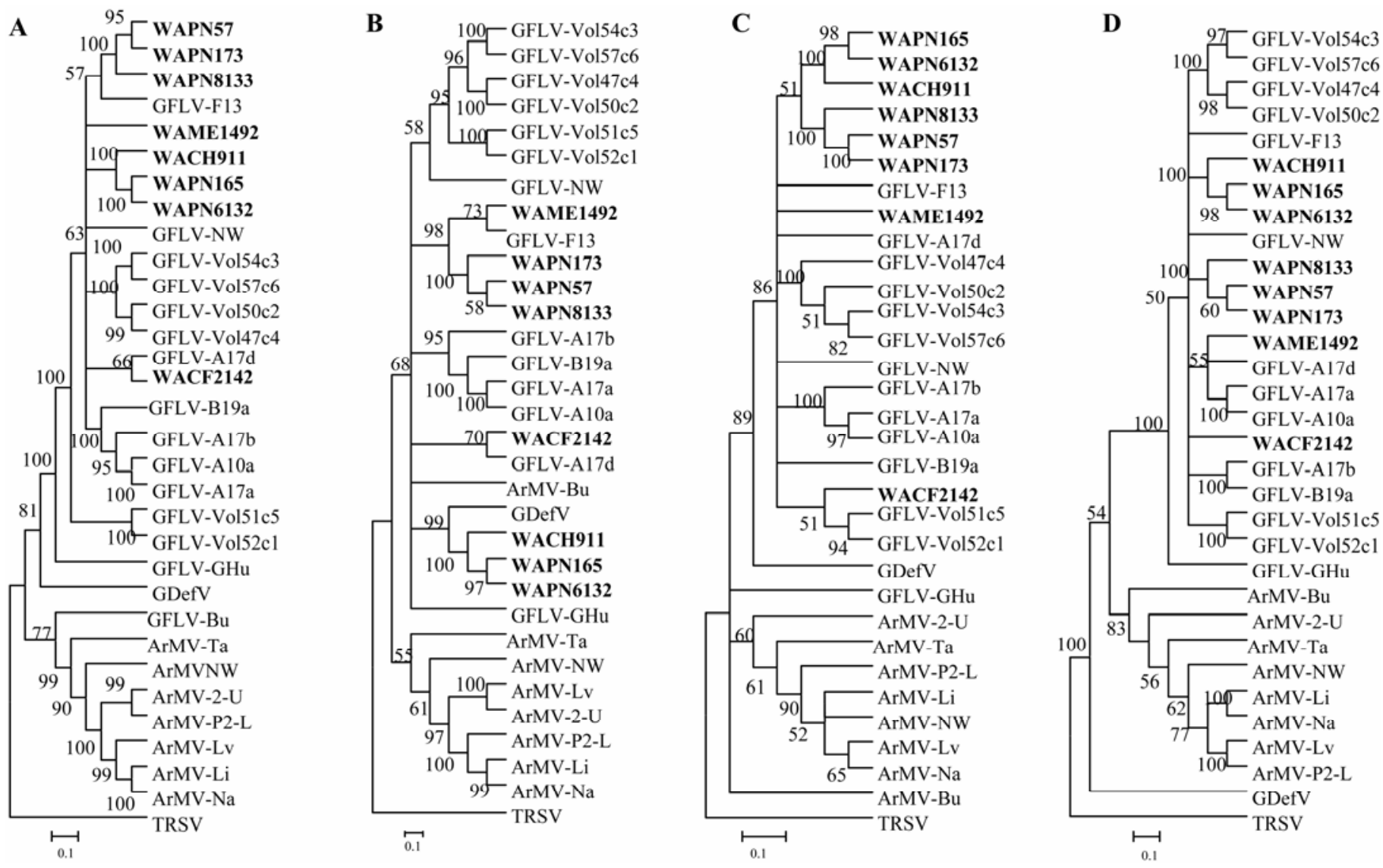

Fig. 3. Phylogenetic consensus trees showing the relationship of RNA2 coding sequence of Grapevine fanleaf virus (GFLV) isolates from Washington State with corresponding sequences of GFLV, Arabis mosaic virus (ArMV), and Grapevine deformation virus (GDefV). The nucleotide sequence of A, RNA2-encoded P2 polyprotein open reading frame; $\mathbf{B}, 2 \mathrm{~A}^{\mathrm{HP}}$ homing protein; $\mathbf{C}, 2 \mathrm{~B}^{\mathrm{MP}}$ movement protein; and $\mathbf{D}, 2 \mathrm{C}^{\mathrm{CP}}$ coat protein were analyzed by the neighbor-joining method in the MEGA4 analysis package. Branch significances were evaluated by constructing 1,000 trees in bootstrap analysis and the bootstrap values ( $\geq 50)$ are shown near the horizontal line at each node. The scale bar under each tree represents genetic distance. GFLV isolates from Washington are in bold. RNA2 sequence of Tobacco ringspot virus (TRSV, NC_005096) was used as an outgroup.

TABLE 3. List of Grapevine fanleaf virus isolates from Washington vineyards showing putative recombination events in RNA1 and RNA2

\begin{tabular}{|c|c|c|c|c|c|c|c|c|c|c|c|}
\hline \multirow{2}{*}{$\begin{array}{l}\text { Recombinant } \\
\text { isolates }^{\mathrm{a}}\end{array}$} & \multirow{2}{*}{$\begin{array}{l}\text { Recombi- } \\
\text { nation site }^{b}\end{array}$} & \multirow{2}{*}{$\begin{array}{l}\text { Gene } \\
\text { region }\end{array}$} & \multirow{2}{*}{$\frac{\text { Parental isolates }^{\mathrm{c}}}{\text { Major } \times \text { minor }}$} & \multicolumn{8}{|c|}{$P$ value $^{\mathrm{d}}$} \\
\hline & & & & $\mathrm{R}$ & G & $\mathrm{B}$ & M & $\mathrm{C}$ & $\mathrm{S}$ & $3 \mathrm{~S}$ & $\mathrm{~L}$ \\
\hline \multicolumn{12}{|c|}{ Interspecies recombination events in RNA2 } \\
\hline WACH911 & $220-489$ & $2 \mathrm{~A}^{\mathrm{HP}}$ & WAPN57×GDefV & $4.88 \times 10^{-34}$ & $4.0 \times 10^{-19}$ & $3.37 \times 10^{-28}$ & $2.69 \times 10^{-11}$ & $9.04 \times 10^{-12}$ & $3.07 \times 10^{-26}$ & $1.23 \times 10^{-21}$ & - \\
\hline WAPN165 & $230-488$ & $2 \mathrm{~A}^{\mathrm{HP}}$ & WAPN57×GDefV & $4.88 \times 10^{-34}$ & $4.88 \times 10^{-34}$ & $3.37 \times 10^{-28}$ & $2.69 \times 10^{-11}$ & $9.04 \times 10^{-12}$ & $3.07 \times 10^{-26}$ & $1.23 \times 10^{-21}$ & - \\
\hline WAPN6132 & $230-489$ & $2 \mathrm{~A}^{\mathrm{HP}}$ & WAPN57×GDefV & $4.88 \times 10^{-34}$ & $4.0 \times 10^{-19}$ & $3.37 \times 10^{-28}$ & $2.69 \times 10^{-11}$ & $9.04 \times 10^{-12}$ & $3.07 \times 10^{-26}$ & $1.23 \times 10^{-21}$ & - \\
\hline WACF2142 & $510-656$ & $2 \mathrm{~A}^{\mathrm{HP}}$ & GFLV-F13×ArMV-Li & $3.54 \times 10^{-07}$ & - & $2.85 \times 10^{-07}$ & $7.99 \times 10^{-03}$ & - & - & $3.44 \times 10^{-04}$ & - \\
\hline WACH911 & $192-463$ & $2 \mathrm{~A}^{\mathrm{HP}}$ & GFLV-F13×ArMV-Bu & $3.26 \times 10^{-09}$ & $7.59 \times 10^{-05}$ & $5.50 \times 10^{-09}$ & $6.17 \times 10^{-14}$ & $5.73 \times 10^{-04}$ & $1.77 \times 10^{-04}$ & $7.82 \times 10^{-13}$ & - \\
\hline WAPN165 & $191-540$ & $2 \mathrm{~A}^{\mathrm{HP}}$ & GFLV-F13×ArMV-Bu & $3.26 \times 10^{-09}$ & $7.59 \times 10^{-05}$ & $5.50 \times 10^{-09}$ & $6.17 \times 10^{-14}$ & $5.73 \times 10^{-04}$ & $1.77 \times 10^{-04}$ & $7.82 \times 10^{-13}$ & - \\
\hline WAPN6132 & $192-468$ & $2 \mathrm{~A}^{\mathrm{HP}}$ & GFLV-F13×ArMV-Bu & $3.26 \times 10^{-09}$ & $7.59 \times 10^{-05}$ & $5.50 \times 10^{-09}$ & $6.17 \times 10^{-14}$ & $5.73 \times 10^{-04}$ & $1.77 \times 10^{-04}$ & $7.82 \times 10^{-13}$ & - \\
\hline WACF 2142 & $1299-1578$ & $2 \mathrm{~A}^{\mathrm{MP}}$ & WAPN173×GDefV & $9.72 \times 10^{-03}$ & - & - & $4.06 \times 10^{-03}$ & $4.60 \times 10^{-04}$ & $3.03 \times 10^{-04}$ & $2.40 \times 10^{-03}$ & $3.72 \times 10^{-54}$ \\
\hline \multicolumn{12}{|c|}{ Intraspecies recombination event in RNA2 } \\
\hline WACF2142 & $1-298$ & $5^{\prime} \mathrm{NCR}-2 \mathrm{~A}^{\mathrm{HP}}$ & GFLV-NW×WAME1492 & $5.58 \times 10^{-07}$ & $5.75 \times 10^{-09}$ & $1.80 \times 10^{-07}$ & $6.47 \times 10^{-05}$ & $1.80 \times 10^{-03}$ & $1.65 \times 10^{-09}$ & - & - \\
\hline \multicolumn{12}{|c|}{ Intraspecies recombination event in RNA1 } \\
\hline WAPN173 & $825-1648$ & $1 \mathrm{~A}-1 \mathrm{~B}^{\mathrm{Hel}}$ & GFLV-F13×WAPN6132 & $1.85 \times 10^{-11}$ & $1.83 \times 10^{-15}$ & $7.11 \times 10^{-16}$ & $7.11 \times 10^{-16}$ & $3.51 \times 10^{-07}$ & $6.44 \times 10^{-17}$ & - & - \\
\hline
\end{tabular}

a Table 1 provides descriptions of virus isolates.

b Numbers indicate nucleotide positions.

c Major and minor parents refer to the parental isolates respectively contributing the larger and smaller fractions of the recombinant's sequence.

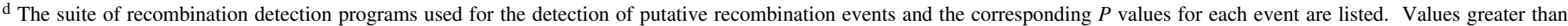
$P=0.05$ are considered significant; - represents no recombination event detected. R, RDP; G, GENECONV; B, BOOTSCAN; M, MAXIMUM $\chi^{2}$; C, CHIMAERA; S, SISCAN; 3S, 3SEQ; and L, LARD. 
isolates studied to date, implying a critical GFLV-specific functional role for them in viral replication or gene expression. The absence of motif 2 in three GFLV isolates and its replacement with a different sequence from ArMV in GFLV-GHu would suggest that this motif may be dispensable, or not as speciesspecific as the other two motifs. We cannot, however, preclude the possibility that motif 2 is essential but its role is compensated in trans by the corresponding motif in RNA1. Whether these stemloop structures contain cis-acting RNA elements essential for RNA replication remain to be determined.

Both ArMV and GDefV have not been documented thus far in Washington vineyards, and we were not able to ascertain the original source of the planting materials of the four cultivars to determine the origin of recombinant isolates. The occurrence of a common recombination site in $2 \mathrm{~A}^{\mathrm{HP}}$ of different isolates from two wine grape cultivars (Chardonnay and Pinot Noir) strongly suggests that the propagation materials have possibly derived originally from vineyards infested with GFLV and GDefV. It is also plausible that the initial source of cuttings of the four cultivars (Cabernet Franc, Pinot Noir, Merlot, and Chardonnay) were derived from scion materials grafted onto common rootstocks where co-infections of GFLV, ArMV, and GDefV occurred due to graft transmission, further increasing the probability of recombination events. The third likely scenario would be that transmission of GFLV by resident $X$. index could have occurred when grapevines already infected with GDefV or ArMV was planted in a vineyard infested with viruliferous nematodes, leading to co-infection of these viruses in the same host. Due to the perennial nature of grapevines, different viruses can persist together in infected plants for many years without being subjected to transmission bottlenecks, which further increases the probability of the generation of recombinant isolates.

In summary, our findings, when considered together with a recent report by Vigne et al. (53), suggested that interspecies recombination occurs in RNA2 of grapevine-infecting nepoviruses and this could be an important strategy for GFLV evolution. From a practical point of view, the generation of viral chimeras could lead to increased genetic diversity and result in the emergence of virus variants that differ in biological properties from common isolates prevailing in a grape-growing area. These new variants are not distinguishable by current serological tests and might severely compromise our ability to gather a true picture of virus variability. Thus, molecular studies such as sequencing of complete genomic RNAs will contribute to an understanding of Nepovirus spp. diversification due to naturally occurring recombinations and biological studies, including nematode transmissions, will offer insights on epidemiological implications of such "novel" variants of nepoviruses. The presence of GFLV isolates causing asymptomatic infections underscores the use of sensitive diagnostic assays for virus testing in clean plant programs. Due to the random distribution of GFLV-infected grapevines, suggestive of virus dissemination via planting materials, sanitation and replanting with virus-tested cuttings will be an effective strategy in eradicating GFLV from virus-infested vineyard blocks. However, sourcing GFLV-infected materials from virus-infested blocks will likely pose a risk of introducing genetic variants of GFLV through planting materials into other grape-growing areas where $X$. index is present.

\section{ACKNOWLEDGMENTS}

This work was supported in part by Washington State University's Agricultural Research Center and Extension Issue-focused Team internal competitive grant, Washington Wine Commission's Wine Advisory Committee, Washington State Department of Agriculture (WSDA)Nursery Assessment Funds and WSDA Specialty Crops Block Grant Program, Washington State Commission on Pesticide Registration, United States Department of Agriculture (USDA)-Agricultural Research
Service Northwest Center for Small Fruits Research, and USDACSREES Viticulture Consortium-West. PPNS no. 0528, Department of Plant Pathology, College of Agricultural, Human, and Natural Resource Sciences Agricultural Research Center Project No. WNPO 0616, Washington State University, Pullman 99164-6240. We thank M. Nita, Virginia Tech, Winchester, VA, for helping with statistical analysis.

\section{LITERATURE CITED}

1. Andret-Link, P., Laporte, C., Valat, L., Laval, L., Ritzenthaler, C., Demangeat, G., Vigne, E., Pfeiffer, P., Stussi-Garaud, C., and Fuchs, M. 2004. Grapevine fanleaf virus: Still a major threat to the grapevine industry. J. Plant Pathol. 86:183-195.

2. Andret-Link, P., Schmitt-Keichinger, C., Demangeat, G., Komar, V., and Fuchs, M. 2004. The specific transmission of Grapevine fanleaf virus by its nematode vector Xiphinema index is solely determined by the viral coat protein. Virology 320:12-22.

3. Bashir, N. S., Zarghani, S. N., and Hejazi, M. S. 2007. Diversity of Grapevine fanleaf virus isolates from Iran. Virus Res. 128:144-148.

4. Belin, C., Schmitt, C., Demangeat, G., Komar, V., Pinck, L., and Fuchs, M. 2001. Involvement of RNA2-encoded proteins in the specific transmission of Grapevine fanleaf virus by its nematode vector Xiphinema index. Virology 291:161-171.

5. Boni, M. F., Posada, D., and Feldman, M. W. 2007. An exact nonparametric method for inferring mosaic structure in sequence triplets. Genetics 176:1035-1047.

6. Boulila, M. 2007. Phylogeny and genetic recombination of Grapevine fanleaf virus isolates from naturally infected vineyards in Tunisia. Phytopathol. Mediterr. 46:285-294.

7. Bovey, R. 1973. Maladies a virus et a mycoplasmes de la vigne. Station Federale de Recherches Agronomiques de Changins, Suisse.

8. Callaway, A., Giesman-Cookmeyer, D., Gillock, E. T., Sit, T. L., and Lommel, S. A. 2001. The multifunctional capsid protein of plant viruses. Annu. Rev. Phytopathol. 39:419-460.

9. Carstens, E. B., and Ball, L. A. 2009. Ratification vote on taxonomic proposals to the International Committee on Taxonomy of Viruses (2008). Arch. Virol. 154:1181-1188.

10. Cigsar, I., Digiaro, M., Gokalp, K., Abou Ghanem-Sabanadzovic, N., De Stradis, A., Boscia, D., and Martelli, G. P. 2003. Grapevine deformation virus, a novel nepovirus from Turkey. J. Plant Pathol. 85:183-191.

11. Dupuis, L., Cobanov, P., Bassler, A., Krczal G., and Wetzel, T. 2008. Complete genome sequence of a virulent isolate of Arabis mosaic virus from privet (Ligustrum vulgare). Arch. Virol. 153:1611-1613.

12. Fattouch, S., Acheche, H., M'hirsi, S., Mellouli, L., Bejar, S., Marrakchi, M., and Marzouki, N. 2005. RT-PCR-RFLP for genetic diversity analysis of Tunisian Grapevine fanleaf virus isolates in their natural host plants. J. Virol. Methods 127:126-132.

13. Gaire, F., Schmitt, C., Stussi-Garaud, C., Pinck, L., and Ritzenthaler, C. 1999. Protein 2A of grapevine fanleaf nepovirus is implicated in RNA2 replication and colocalizes to the replication site. Virology 264:25-36.

14. García-Arenal, F., Fraile, A., and Malpica, J. M. 2001. Variability and genetic structure of plant virus populations. Annu. Rev. Phytopathol. 39:157-186.

15. Ghanem-Sabanadzovic, N. A., Sabanadzovic, S., Digiaro, M., and Martelli, G. P. 2005. Complete nucleotide sequence of the RNA-2 of Grapevine deformation and Grapevine anatolian ringspot viruses. Virus Genes 30:335-340.

16. Gibbs, M. J., Armstrong, J. S., and Gibbs, A. J. 2000. Sister-scanning: a Monte Carlo procedure for assessing signals in recombinant sequences. Bioinformatics 16:573-582.

17. Hewitt, W. B., Raski, D. J., and Goheen, A. C. 1958. Nematode vector of soil-borne fanleaf virus of grapevines. Phytopathology 48:586-595.

18. Holmes, E. C., Worobey, M., and Rambaut, A. 1999. Phylogenetic evidence for recombination in dengue virus. Mol. Biol. Evol. 16:405-409.

19. Huss, B., Walter, B., and Fuchs, M. 1989. Cross-protection between Arabis mosaic virus and Grapevine fanleaf virus in Chenopodium quinoa. Ann. Appl. Biol. 114:45-60.

20. Imura, Y., Oka, H., Kimata, K., Nasu, M., Nakahama, K., and Maeda, T. 2008. Comparisons of complete RNA-2 sequences, pathological and serological features among three Japanese isolates of Arabis mosaic virus. Virus Genes 37:333-341.

21. Le Gall, O., Iwanami, T., Jones, A. T., Lehto, K., Sanfacon, H., Wellink, J., Wetzel, T., and Yoshikawa, N. 2005. Comoviridae. Pages 807-818 in: Virus Taxonomy, Eighth Report of the International Committee on the Taxonomy of Viruses. C. M. Fauquet, M. A. Mayo, J. Maniloff, U. Desselberger, and L. A. Ball, eds. Elsevier Academic Press, London .

22. Le Gall, O., Lanneau. M., Candresse, T., and Dunez, J. 1995. The nucleotide sequence of the RNA-2 of an isolate of the English serotype of Tomato black ring virus: RNA recombination in the history of 
nepoviruses. J. Gen. Virol. 76:1279-1283.

23. Legin, R., Bass, P., Etienne, L., and Fuchs, M. 1993. Selection of mild virus strains of fanleaf degeneration by comparative field performance of infected grapevines. Vitis 32:103-110.

24. Liebenberg, A., Freeborough, M.-J., Visser, C. J., Bellstedt, D. U., and Burger, J. T. 2009. Genetic variability within the coat protein gene of Grapevine fanleaf virus isolates from South Africa and the evaluation of RT-PCR, DAS-ELISA and ImmunoStrips as virus diagnostic assays. Virus Res. 142:28-35.

25. Loudes, A. M., Ritzenthaler, C., Pinck, M., Serghini, M. A., and Pinck, L. 1995. The $119 \mathrm{kDa}$ and $124 \mathrm{kDa}$ polyproteins of Arabis mosaic nepovirus (isolate S) are encoded by two distinct RNA2 species. J. Gen. Virol. 76:899-906.

26. Margis, R., Ritzenthaler, C., Reinbolt, J., Pinck, M., and Pinck, L. 1993. Genome organization of Grapevine fanleaf nepovirus RNA2 deduced from the $122 \mathrm{~K}$ polyprotein P2 in vitro cleavage products. J. Gen. Virol. 74:1919-1926.

27. Martelli, G. P., and Taylor, C. E. 1990. Distribution of viruses and their nematode vectors. Pages 151-189 in: Advances in Disease Vector Research, Vol. 6. K. Harris, ed. Springer-Verlag, New York.

28. Martin, D., and Rybicki, E. 2000. RDP: detection of recombination amongst aligned sequences. Bioinformatics 16:562-563.

29. Martin, D. P., Williamson, C., and Posada, D. 2005. RDP2: Recombination detection and analysis from sequence alignments. Bioinformatics 21:260-262.

30. Mekuria, T., Martin, R. R., and Naidu, R. A. 2008. First report of the occurrence of Grapevine fanleaf virus in Washington State vineyards. Plant Dis. 92:1250.

31. Nagy, P. D. 2008. Recombination in plant viruses. In: Plant Virus Evolution. M. J. Roossink, ed. Springer-Verlag, Berlin, Heidelberg.

32. Naraghi-Arani, P., Daubert, S., and Rowhani, A. 2001. Quasispecies nature of the genome of Grapevine fanleaf virus. J. Gen. Virol. 82:1791-1795.

33. Ohshima, K., Tomitaka, Y., Wood, J. T., Minematsu, Y., Kajiyama, H., Tomimura, K., and Gibbs, A. J. 2007. Patterns of recombination in Turnip mosaic virus genomic sequences indicate hotspots of recombination. J. Gen. Virol. 88:298-315.

34. Padidam, M., Sawyer, S., and Fauquet, C. 1999. Possible emergence of new geminiviruses by frequent recombination. Virology 265:218-225.

35. Page, R. D. M. 1996. TREEVIEW: an application to display phylogenetic trees on personal computers. Comput. Appl. Biosci. 12:357-358.

36. Pink, M., Reinbolt, J., Loudes, A. M., Le Ret, M., and Pink, L. 1991. Primary structure and location of the genome-linked protein $(\mathrm{VPg})$ of Grapevine fanleaf nepovirus. FEBS Lett. 284:117-119.

37. Pompe-Novak, M., Gutiérrez-Aguirre, I., Vojvoda, J., Blas, M., Tomažic, I., Vigne, E., Fuchs, M., Ravnikar, M., and Petrovic, N. 2007. Genetic variability within RNA2 of Grapevine fanleaf virus. Eur. J. Plant Pathol. 117:307-312.

38. Posada, D., and Crandall, K. A. 2001. Evaluation of methods for detecting recombination from DNA sequences: Computer simulations. Proc. Natl. Acad. Sci. USA 98:13757-13762.

39. Posada, D., Crandall, K. A., and Holmes, E. C. 2002. Recombination in evolutionary genomics. Annu. Rev. Genet. 36:75-97.

40. Qiu, W., Avery, J. D., and Lunden, S. 2007. Characterization of a severe virus-like disease in Chardonnay grapevines in Missouri. Online. Plant
Health Progress doi:10.1094/PHP-2007-1119-01-BR.

41. Quacquarelli, A., Gallitelli, D., Savino, V., and Martelli, G. P. 1976. Properties of Grapevine fanleaf virus. J. Gen. Virol. 32:349-360.

42. Raski, D. J., Goheen, A. C., Lider, L. A., and Meredith, C. P. 1983. Strategies against Grapevine fanleaf virus and its nematode vector. Plant Dis. 67:335-339.

43. Ritzenthaler, C., Pinck, M., and Pinck, L. 1995. Grapevine fanleaf nepovirus $\mathrm{P} 38$ putative movement protein is not transiently expressed and is a stable final maturation product in vivo. J. Gen. Virol. 76:907-915.

44. Ritzenthaler, C., Viry, M., Pinck, M., Margis, R., Fuchs, M., and Pinck, L. 1991. Complete nucleotide sequence and genetic organization of Grapevine fanleaf nepovirus RNA1. J. Gen. Virol. 72:2357-2365.

45. Rowhani, A., Biardi, L., Johnson, R., Saldarelli, P., Zhang. Y. P., Chin, J., and Green, M. 2000. Simplified sample preparation method and one-tube RT-PCR for grapevine viruses. In: Proc. XIII Meet. Int. Counc. Study of Virus-like Diseases of the Grapevine (ICVG), Adelaide, Australia.

46. Rowhani A., Chay, C., Golino, D. A., and Falk, B. W. 1993. Development of a polymerase chain reaction technique for the detection of Grapevine fanleaf virus in grapevine tissue. Phytopathology 83:749-753.

47. Serghini, M. A., Fuchs, M., Pinck, M., Reinbolt, J., Walter, B., and Pinck, L. 1990. RNA2 of Grapevine fanleaf virus: Sequence analysis and coat protein cistron location. J. Gen. Virol. 71:1433-1441.

48. Smith, J. M. 1992. Analyzing the mosaic structure of genes. J. Mol. Evol. 34:126-129.

49. Tamura, K., Dudley, J., Nei, M., and Kumar, S. 2007. MEGA4: Molecular Evolutionary Genetics Analysis (MEGA) software version 4.0. Mol. Biol. Evol. 24:1596-1599.

50. Thompson, J. D., Higgins, D. G., and Gibson, T. J. 1994. CLUSTAL W: Improving the sensitivity of progressive multiple sequence alignment through sequence weighting, positions-specific gap penalties and weigh matrix choice. Nucleic Acid. Res. 22:4673-4680.

51. Vigne, E., Bergdoll, M., Guyader, S., and Fuchs, M. 2004. Population structure and genetic variability within isolates of Grapevine fanleaf virus from a naturally infected vineyard in France: Evidence for mixed infection and recombination. J. Gen. Virol. 85:2435-2445.

52. Vigne, E., Demangeat, G., Komar, V., and Fuchs, M. 2005. Characterization of a naturally occurring recombinant isolate of Grapevine fanleaf virus. Arch. Virol. 150:2241-2255.

53. Vigne, E., Marmonier, A., and Fuchs, M. 2008. Multiple interspecies recombination events within RNA2 of Grapevine fanleaf virus and Arabis mosaic virus. Arch. Virol. 153:1771-1776.

54. Vigne, E., Marmonier, A., Komar, V., Lemaire, O., and Fuchs, M. Genetic structure and variability of virus populations in cross-protected grapevines superinfected by Grapevine fanleaf virus. Virus Res. 144:154-162.

55. Viry, M., Serghini, M. A., Hans, F., Ritzenthaler, C., Pinck, M., and Pinck, L. 1993. Biologically active transcripts from cloned cDNA of genomic grapevine fanleaf nepovirus RNAs. J. Gen. Virol. 74:169-174.

56. Wetzel, T., Chisholm, J., Bassler, A., and Sanfaçon, H. 2008. Characterization of proteinase cleavage sites in the $\mathrm{N}$-terminal region of the RNA1-encoded polyprotein from Arabis mosaic virus (subgroup A nepovirus). Virology 375:159-169.

57. Wetzel, T., Meunier, L., Jaeger, U., Reustle, G. M., and Krczal, G. 2001. Complete nucleotide sequences of the RNAs 2 of German isolates of Grapevine fanleaf and Arabis mosaic nepoviruses. Virus Res. 75:139-145. 